\title{
Observed and modelled solar radiation components in sugarcane crop grown under tropical conditions
}

\author{
Marcos A. dos Santos ${ }^{1}$, José L. de Souza ${ }^{1 *}$, Gustavo B. Lyra ${ }^{2}$, Iêdo Teodoro ${ }^{1}$, Ricardo A. Ferreira Junior ${ }^{1}$, \\ Alexsandro C. dos Santos Almeida ${ }^{3}$, Guilherme B. Lyra ${ }^{1}$, Renan C. de Souza, \\ and Marco A. Maringolo Lemes ${ }^{1}$ \\ ${ }^{1}$ Department of Agrometeorology, Federal University of Alagoas, Maceió-AL, Brazill \\ ${ }^{2}$ Department of Meteorology and Climatology, Federal Rural University of Rio de Janeiro, Seropédica-RJ, Brazil \\ ${ }^{3}$ Agricultural Science Faculty, Federal University of Grande Dourados, Dourados-MS, Brazil
}

Received August 24, 2016 accepted April 5, 2017

\begin{abstract}
A b s t r a c t. The net radiation over vegetated surfaces is one of the major input variables in many models of soil evaporation, evapotranspiration as well as leaf wetness duration. In the literature there are relatively few studies on net radiation over sugarcane crop in tropical climates. The main objective of the present study was to assess the solar radiation components measured and modelled for two crop stages of a sugarcane crop in the region of Rio Largo, Alagoas, North-eastern Brazil. The measurements of the radiation components were made with a net radiometer during the dry and rainy seasons and two models were used to estimate net radiation: the Ortega-Farias model and the Monteith and Unsworth model. The highest values of net radiation were observed at the crop development stage, due mainly to the high indices of incoming solar radiation. The daily average albedos of sugarcane at the crop development and mid-season stages were 0.16 and 0.20 , respectively. Both models showed a better fit for the crop development stage than for the mid-season stage. When they were inter-compared, Monteith and Unsworth model was more efficient than Ortega-Farias model, despite the dispersion of their simulated radiation components which was similar.

$\mathrm{K}$ e y w o r d s: sugarcane, albedo, net radiation
\end{abstract}

\section{INTRODUCTION}

Sugarcane (Saccharum ssp.) is an agricultural crop of great economic importance because it has a strategic role in sugar production and energy generation, which, for instance, in Brazil represents $17 \%$ of primary energy. The culture reaches high level of yield when management practices (such as sowing, plant density, nutrition and plant protections) appropriate to the actual agro-environmental requirements are adopted. Thus, research aimed at improv-

*Corresponding author e-mail: jls@ccen.ufal.br ing agricultural productivity must consider the interactions between production factors and meteorological variables, in particular the solar radiation.

The net radiation $\left(R_{n}\right)$ over the surface is determined by computing the incoming radiation and the outgoing radiation. The incoming radiation consists of the solar or shortwave radiation $\left(R_{s}\right)$ and the emitted longwave radiation by the atmosphere $\left(R_{l, a}\right)$. The outgoing radiation includes the reflected solar radiation $\left(R_{s, r}\right)$ and emitted longwave radiation by the surface $\left(R_{l, s}\right)$; that is, $R_{n}$ is the sum of the net shortwave $\left(R_{n, s}=R_{s}-R_{s, r}\right)$ and net longwave $\left(R_{n, l}=R_{l, a}\right.$ $-R_{l, s}$ ) radiation. The magnitude of $R_{n}$ is related to the intensity of its components with $R_{s}$ and $R_{l, a}$ being dependent on the latitude, season and global atmospheric transmittance. $R_{s, r}$ and $R_{l, s}$ change with the optical properties of the surface (reflectivity and emissivity) which depend on the fraction of covered surface, crop height and the incidence angle of the solar rays (Souza et al., 1999).

The quantification of $R_{n}$ over vegetated surfaces is imporant for the photosynthetic process and dimensioning of the energy requirements (Inman-Bamber and Mcglinchay, 2003; Mkhwanazi et al., 2015), necessary to produce useful estimates of the actual water demand of the crops (Paltineanu et al., 2012). Thereby, $R_{n}$ is one of the major input variables in soil evaporation models (Black et al., 1970), evapotranspiration models (Monteith and Unsworth, 1990) and hybrid models that estimate evaporation and transpiration separately (Kato et al., 2004). Furthermore, $R_{n}$ is also used in models that produce estimates of the

(C) 2017 Institute of Agrophysics, Polish Academy of Sciences 
period of leaf wetness (Sentelhas and Gillespie, 2008). Measurements of $R_{n}$ using net radiometers are not routinely made at the meteorological stations due to the peculiarities of each surface and shorter calibration intervals (Llasat and Snyder, 1998). Also, it is a well-documented fact that there are differences among $R_{n}$ measurements made by different net radiometers (Kustas et al., 1998). Considering all that, empirical or semi empirical models appear as a promising alternative to estimate $R_{n}$.

In the empirical models, $R_{n}$ is determined from linear relationship with $R_{s}$ or $R_{n, s}$. The coefficients of such relationship are valid only for given localities, season and specific coverage (Alados et al., 2003). Conversely, semi-empirical models are based on $R_{n, s}$ and $R_{n, l}$ estimates and have been an important alternative to compute $R_{n}$ when it is not measured (Fontana et al., 1991; Ortega-Farías et al., 2000). The major difference between these approaches results from the difficulty in estimating $R_{n, l}$, considering that it is obtained from the relation $(1-\alpha) R_{s}$, where $\alpha$ is the albedo given by $R_{s, r} / R_{s}$. Albedo is an important characteristic variable of the surface obtained by remote sensing techniques (Peng et al., 2015); nevertheless its validation still requires conventional radiometric measurements.

The usefulness of $R_{n}$ in biophysical processes is related to energy and water transfer in the soil-plant-atmosphere system (for each type of surface) and it motivated researchers to seek for $R_{n}$ estimates using meteorological variables more routinely measured. In this sense several semi-empirical models were developed and tested, providing useful $R_{n}$ estimates over different surface conditions and for different purposes (Carrasco and Ortega-Farias, 2008; Ortega-Farias et al., 2000; Sentelhas and Gillespie, 2008). Since the estimate errors are quite close to those of the instruments, some authors concluded that these models can replace $R_{n}$ measurements in estimating evapotranspiration rates (Carrasco and Ortega-Farias, 2008; Ortega-Farias et al, 2000) and leaf wetness duration (Sentelhas and Gillespie, 2008). Since there are relatively few studies (André et al., 2010; Azevedo et al., 2014) in the literature on net radiation over sugarcane crops in Tropical climates, the objective of this paper was to assess and model the solar radiation components for two growth stages of sugarcane crop under tropical climate conditions on the eastern coast of north-eastern Brazil.

\section{MATERIAL AND METHODS}

The field experiment of this study was carried out at the Centro de Ciências Agrárias /Universidade Federal de Alagoas (CECA/UFAL) in Rio Largo, Alagoas state, North-eastern Brazil (09 28'02” S; 35 49'43” W; 127 $\mathrm{m}$ ) in a sugarcane crop (variety RB 92579 ) under rainfed conditions, from 16th September 2005 (sowing) to 30th November 2006 (harvest). The climate of the region is classified as megathermal or humid tropical with mean annual precipitation of $1818 \mathrm{~mm}$, wherein a rainy period extends from March to August (concentrating 78\% of the annual total precipitation) and a dry period occurs from September to February. The air temperature varies from 19.3 (August) to $31.7^{\circ} \mathrm{C}$ (January), with annual average of $25.4^{\circ} \mathrm{C}$. Further climatic information on the region can be found elsewhere (Souza et al., 2005). The soil at the location is a cohesive argisolic yellow latosol of medium clay texture and bulk density of $1500 \mathrm{~kg} \mathrm{~m}^{-3}$.

Evaluations of the expanded leaf number (ELN) together with leaf length (L) and width (W) measurements were made monthly during the whole growth cycle of the crop. The beginning of the biometric evaluations was 60 days after planting (DAP) and lasted until 411 DAP. The leaf area (LA) of each plant was determined [ $(0.75 x \mathrm{~L} x W) x$ $(\mathrm{ELN}+2)]$ and used to compute the leaf area index (LAI) - ratio between LA and the soil surface area of the crop. The estimates of the daily LAI in the crop cycle were made using a polynomial equation in terms of the DAP. The duration of the growth stages of the sugarcane crop were determined using the LAI and the duration of the growth crop stages - initial (60 days), crop development (124 days), mid-season (196 days) and late season (60 days) for the local climatic conditions (Allen et al., 1998). Details of the main environmental and agronomical characteristics are found in Teodoro et al. (2009).

The measurements $\left(\mathrm{W} \mathrm{m}^{-2}\right)$ of the radiation components (incoming and reflected solar radiation, emitted longwave radiation by the atmosphere and by the surface) were obtained using a net radiometer (CNR1, Kipp and Zonen, Holland) placed $0.5 \mathrm{~m}$ above the canopy of the crop, with a fetch of approximately $150 \mathrm{~m}$. The experiment area was surrounded by commercial crops of sugarcane. The measurements were made using a datalogger (CR10X, Campbell Scientific Inc., USA) recording at every $10 \mathrm{~s}$, with the averages stored at every $10 \mathrm{~min}$. The meteorological variables (air temperature and relative humidity) required to estimate $R_{n}$ by the models were obtained from a nearby agrometeorological station, situated $200 \mathrm{~m}$ away from the experiment site. Data of rainfall and meteorological variables required to compute the reference evapotranspiration (ETo) by the standard FAO-Penman-Monteith method (Allen et al., 1998) were also collected from the same weather station throughout the sugarcane crop cycle period.

The net radiation and its components were evaluated in two different periods of the sugarcane cycle, which differed in the meteorological conditions and fraction of covered soil. The first period began on 17th February and ended on 24th February 2006 (dry season); the second extended from 3rd June until 27th June 2006 (rainy season).

Two empirical models:

- the model proposed by Ortega-Farias et al. (2000) (OFM) and

- a derived model from Monteith and Unsworth (1990) (MUM) were used with these data as input in order to estimate hourly $R_{n}$. 
The OFM was further simplified by obtaining $R_{l, a}$ as suggested in Brutsaert (1982), that is:

$$
R_{n}=R_{n, s}+R_{n, l}=(1-\alpha) R_{s}+\varepsilon_{s}\left[1.31\left(e_{a} / T_{a}\right)^{1 / 7}-1\right] \sigma T_{s}^{4},
$$

where: $\alpha$ is the crop albedo, $\varepsilon_{s}(0.995)$ is the crop emissivity (Idso et al., 1969), $T_{a}(\mathrm{~K})$ is the absolute air temperature and $T_{s}(\mathrm{~K})$ the canopy absolute temperature, assumed equal to $T_{a}, \sigma\left(5.6710^{-8} \mathrm{~W} \mathrm{~m}^{-2} \mathrm{~K}^{-4}\right)$ is the Stefan-Boltzman constant, and $e_{a}(\mathrm{hPa})-$ actual atmospheric water vapour pressure, given by:

$$
e_{a}=R H 6.108 \exp \left(\frac{17.27 T_{a}}{237.3+T_{a}}\right),
$$

where $R H$ is a relative humidity (\%).

The estimate of the longwave radiation in the MUM model is made using an empirical relationship with $T_{a}$ corrected by the clearness index or global atmospheric transmittance $\left(K_{t}\right)$. Thus, $R_{n}$ is given by:

$$
R_{n}=R_{n, s}+R_{n, l}=(1-\alpha) R_{s}+f\left(K_{t}\right)\left(0.0003 T_{a}-0.107\right),
$$

where: $f\left(K_{t}\right)$ is a correction function regarding the cloudiness. Under clear sky conditions, $f\left(K_{t}\right)=1$, and under cloudy sky it is:

$$
f\left(K_{t}\right)=1-\frac{1}{1+0.034 \exp \left(7.9 K_{t}\right)},
$$

$K_{t}$ is defined as the ratio between the solar radiation at the surface and the solar radiation at the top of the atmosphere $\left(R_{a}\right)$. Days with $K_{t} \geq 0.7$ were classified as clear sky, $0.3<$ $K_{t}<0.7$ as partially cloudy sky, and $K_{t}<0.3$ as overcast sky (Iqbal, 1983). For the albedo, computed daily values obtained as the ratio between reflected solar radiation $\left(R_{s}, r\right)$ and $R_{s}$ were used. Daily values of the radiation components

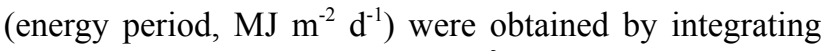
its respective measurements $\left(\mathrm{W} \mathrm{m}^{-2}\right)$ from 05:00 local time (LT) to 18:00 LT.

The performance of the models evaluated was based on the following statistical indices: determination coefficient $\left(r^{2}\right)$, angular coefficient of the simple linear regression (b) between observed and estimated $R_{n}$, mean absolute error $(M A E)$ and the root mean square error (RMSE), given by the following formulae (Willmott, 1985):

$$
\begin{gathered}
\text { MAE }=\frac{\sum_{i=1}^{n}\left(\left|P_{i}-O_{i}\right|\right)}{n}, \\
R M S E=\sqrt{\frac{\sum_{i=1}^{n}\left(P_{i}-O_{i}\right)^{2}}{n},}
\end{gathered}
$$

where: $P_{i}$ is the estimated value given by the model, $O_{i}$ the observed value and $n$ the number of observations.

\section{RESULTS AND DISCUSSIONS}

For the analysed period (17-24 Febreuary) of the crop development stage (Fig. 1), $R_{s}$ ranged from 12.6 to $26.5 \mathrm{MJ}$ $\mathrm{m}^{-2} \mathrm{~d}^{-1}$ (average $21.8 \pm 5.4 \mathrm{MJ} \mathrm{m}^{-2} \mathrm{~d}^{-1}$ ). For the same period, the average $K_{t}$ was $0.59 \pm 0.14$. However, for the mid-season stage (3-27 June), $R_{s}$ was smaller than that of the crop development stage, between 6.8 and $17.5 \mathrm{MJ} \mathrm{m}^{-2} \mathrm{~d}^{-1}$ (average $12.6 \pm 2.65 \mathrm{MJ} \mathrm{m}^{-2} \mathrm{~d}^{-1}$ ), while the average $K_{t}$ was 0.49 \pm 0.10 . The differences in $R_{s}$ between the stages were due mainly to measurements in the crop development stage being carried out in the dry season (Southern Hemisphere summer - large $R_{a}$ ), characterised by less cloudiness (large $K_{t}$ values), while in the mid-season stage the measurements coincided with the rainy season (Southern Hemisphere winter - small $R_{a}$ ), large cloudiness and lower $K_{t}$ (Souza et al., 2005). The differences between the $R_{s}$ in these two periods determined the differences in the net radiation components. $R_{n}$ varied from 7.8 to $16.5 \mathrm{MJ} \mathrm{m}^{-2} \mathrm{~d}^{1}$ (average 13.3 $\pm 3.4 \mathrm{MJ} \mathrm{m}^{-2} \mathrm{~d}^{1}$ ) during the crop development stage, and from 4.8 to $11.8 \mathrm{MJ} \mathrm{m}^{2} \mathrm{~d}^{1}$ (average $8.5 \pm 1.89 \mathrm{MJ} \mathrm{m}^{2} \mathrm{~d}^{1}$ ) during the mid-season stage. As the changes in $R_{n}$ were mainly caused by $R_{s}$ changes (Fig. 1), the smallest values of radiation density were observed during the mid-season stage. During this period, the average $R_{s}$ was $73 \%$ lower than that of the crop development stage, but the separated analysis of LAI in these two stages revealed a small increase in $R_{n}$ with LAI.

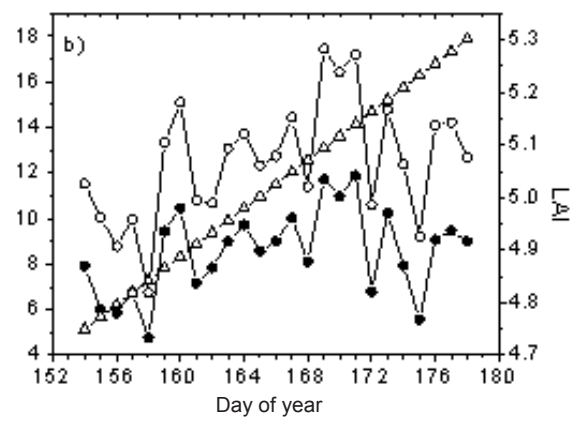

Fig. 1. Solar radiation $\left(R_{s}\right)$, net radiation $\left(R_{n}\right)$ and leaf area index (LAI, $\mathrm{m}^{2} \mathrm{~m}^{-2}$ ) during the: a - crop development stage and $\mathrm{b}-\mathrm{mid}-$ season stage of a sugarcane crop in Rio Largo region, a coastal area of Alagoas state, Brazil. 

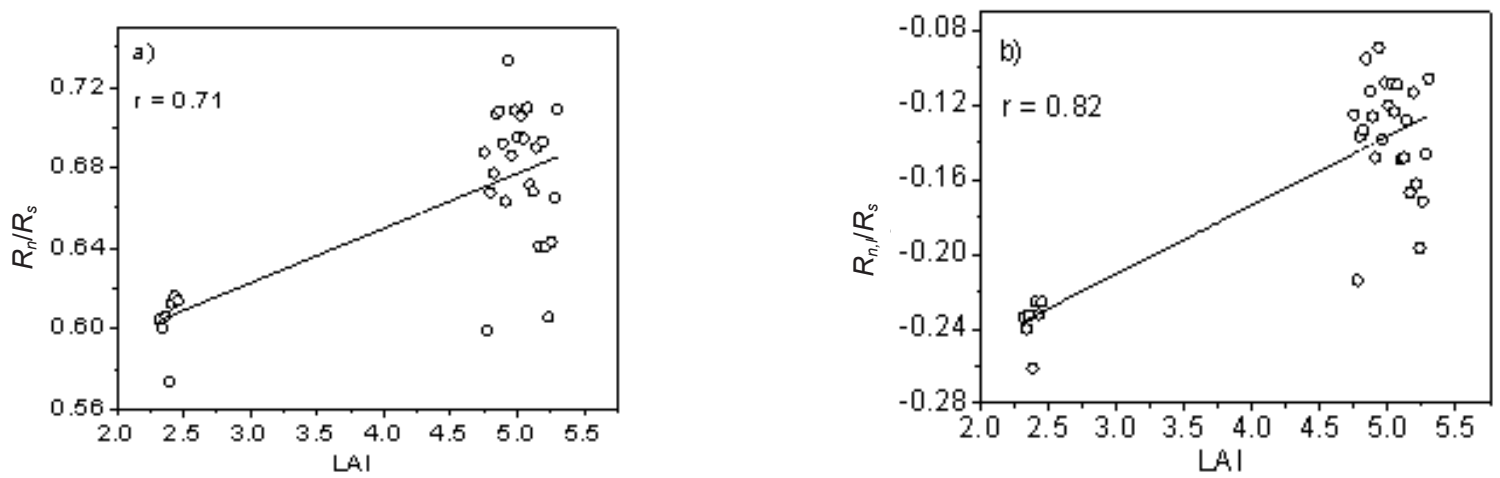

Fig. 2. Linear relationships between: a - net radiation and solar radiation $\left(R_{n} / R_{s}\right), \mathrm{b}$ - net long wave radiation and global solar radiation $\left(R_{n, l} / R_{s}\right)$ as a function of the leaf area index (LAI) in a sugarcane crop in Rio Largo region, a coastal area of Alagoas state, Brazil.

The dependence of $R_{n}$ on IAF can be better analysed by normalising $R_{n}$ with respect to $R_{s}$, i.e. by the $R_{n} / R_{s}$ ratio. As shown in Fig. 2 , the $R_{n} / R_{s}$ ratio increases with LAI, thus being higher during the mid-season stage (61.1 and $67.9 \%$ for crop development and mid-season stages, respectively). This result indicates that simple empirical models given by a linear relationship between $R_{n}$ and $R_{g}$ may not be suitable for annual crops such as sugarcane with IAF varying considerably throughout the crop cycle. An alternative would be a relationship between the $R_{n} / R_{g}$ ratio and IAF or multilinear regression models including IAF in their formulation. The $R_{n} / R_{g}$ ratio and $R_{n, l}$ have been reported for several crops and types of vegetation (Fontana et al., 1991; Souza and Escobedo, 1997; Souza et al., 2010; Teixeira, 2001; Teixeira et al., 2008; Zhang et al., 2010), from which different relationships can be found. For instance, Souza and Escobedo (1997) found an inverse relationship between $R_{n} / R_{s}$ and LAI for bean crop, Teixeira (2001) reported a direct linear relationship whereas no relation was found by Fontana et al. (1991) for a soybean crop under soil total- ly covered. The $R_{n} / R_{s}$ ratio is given by the sum of two terms: $R_{n, l} / R_{s}$ and (1- $\alpha$ ), this ratio being always negative (Fig. $2 \mathrm{~b}$ ), but its absolute values are about $45.5 \%$ higher during the crop development stage (average of -0.22) with respect to the mid-season stage. The $(1-\alpha)$ term was, on average, 0.83 and 0.80 for the crop development and mid-season stages, respectively, a difference less than $3.6 \%$. The decrease of the $R_{n} / R_{s}$ ratio during the crop development stage may be attributed to the higher absolute values of the $R_{n, l} / R_{s}$ ratio, which was associated with the soil water deficit - although soil water content was not measured, soil water deficit can be inferred by the difference between P and ETo (Fig. 3). In turn, this is responsible for an increase in the leaf temperature and, consequently, larger emissions of longwave radiation during periods of hydric stress. In addition, the crop development (mid-season) stage occurred in the dry (rainy) period, which has less (more) clouds and air humidity. Therefore, larger (smaller) losses of longwave radiation are observed during the crop development (mid-season) stages.

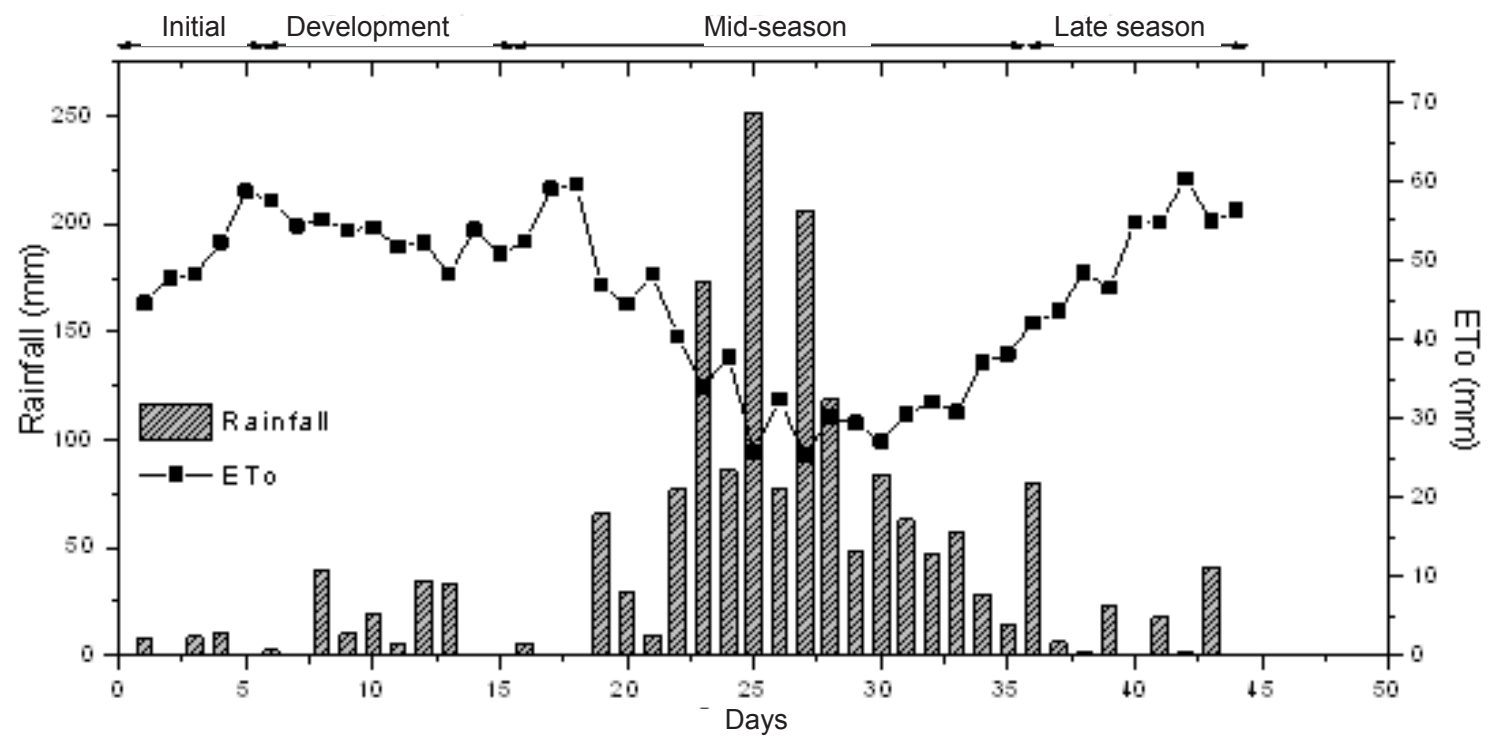

Fig. 3. Accumulated rainfall and reference evapotranspiration of ten days throughout the sugarcane crop cycle in Rio Largo region, a coastal area of Alagoas state, Brazil. The corresponding crop stages are indicated at the top. 


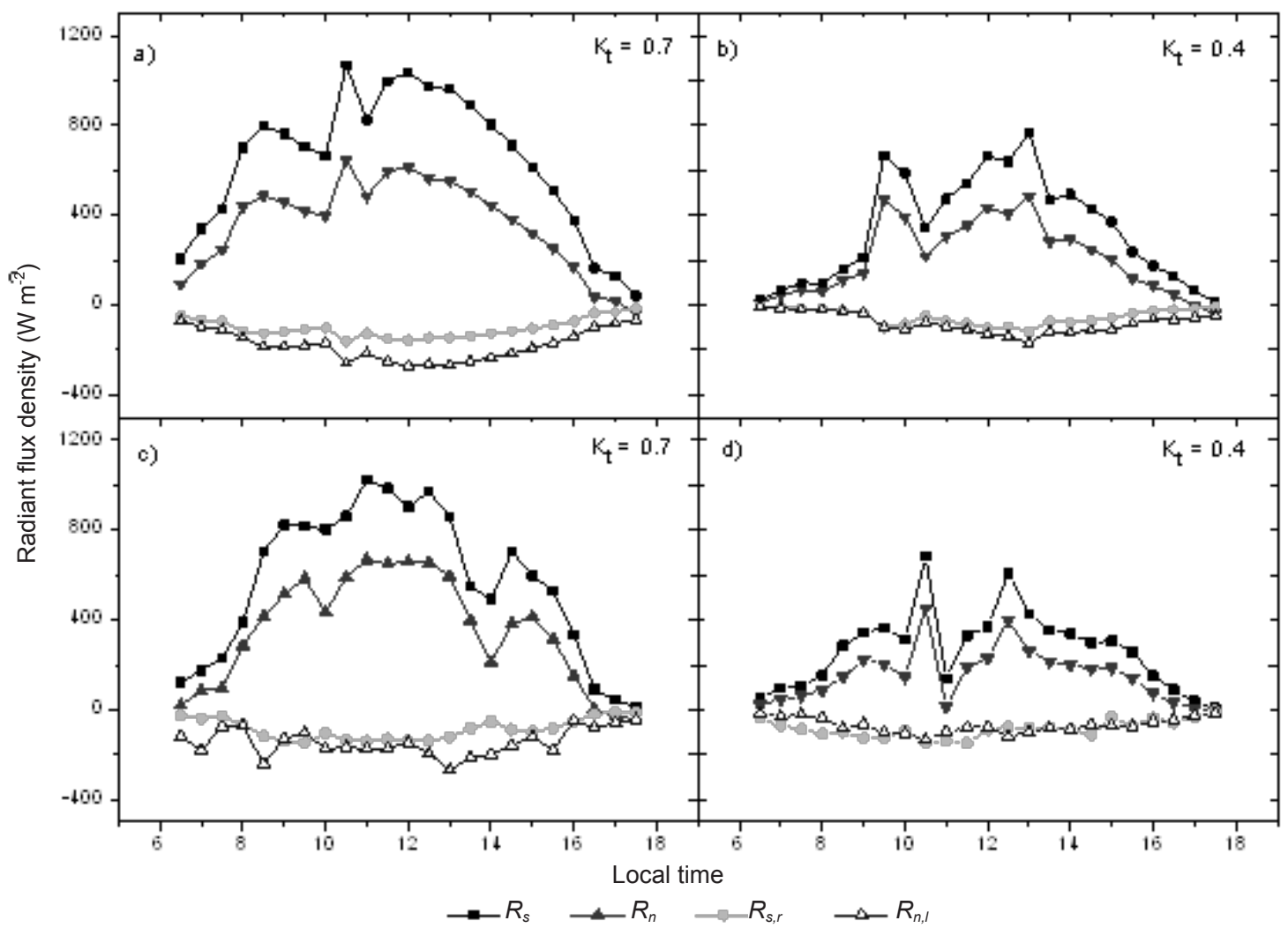

Fig. 4. Incoming solar radiation $\left(R_{s}\right)$, net radiation $\left(R_{n}\right)$, reflected solar radiation $\left(R_{s, r}\right)$ and net longwave radiation $\left(R_{n, l}\right)$ in clear sky $(\mathrm{a}, \mathrm{c})$ and partially cloudy sky (b, d) for the crop development (a, b) and mid-season stages (c, d) of a sugarcane crop in Rio Largo region, a coastal area of Alagoas state, Brazil. $K_{t}$ is the clearness index, defined as the ratio between the solar radiation at surface and the solar radiation at the top of the atmosphere.

The radiation losses in a crop are made up of $R_{s, r}$ and $R_{n, l}$. The largest losses during the crop development (mid-season) stage were due to the $R_{n, l}\left(R_{s, r}\right)$ term. The $R_{s, r}$ difference between the two stages was only $9.6 \%$ while the $R_{n, l}$ difference was $224 \%$. The high values of $R_{n, l}$ found during the crop development stage may be attributed to the high temperatures of the soil-plant system, modulated by the soil water deficit, and consequently, low evapotranspiration.

Cloudiness exerted some influence on the daily changes and magnitudes of $R_{n}$ and its components. Although deviations were observed in the daily $R_{n}$ during clear sky conditions (Fig. 4a, c), smooth fluctuations were evident as opposed to partially cloudy sky conditions (Fig. 4b, d) when the presence of abrupt changes during the day were present. The daily totals of $R_{n}, R_{s, r}$ and $R_{n, l}$ for days of the mid-season stage with $K_{t}=0.36$ (partially cloudy sky) were, respectively, 7.8, 2.1 and $-2.8 \mathrm{MJ} \mathrm{m}^{-2}$, while for $K_{t}=0.71$ (clear sky), these values were $5.9 \mathrm{MJ} \mathrm{m}^{-2}\left(R_{n}\right), 4.2$ $\mathrm{MJ} \mathrm{m}^{-2}\left(R_{s, r}\right)$ and $-6.2 \mathrm{MJ} \mathrm{m}^{-2}\left(R_{n, l}\right)$.

Independently of the growth stage, larger amplitudes of the albedo occurred under clear sky days (Fig. 5). The daily variation of albedo is influenced by the cloud cover, but this dependence is not found when the albedo is obtained by the daily total radiation (Souza et al., 1999). It was also noted that the daily albedo fluctuations were the largest during the mid-season stage, when the soil was completely covered with the vegetation. Alves et al. (1998) also observed the same.

The daily albedo of the crop varied from 0.15 to 0.17 (average $0.16 \pm 0.004$ ) during the crop development stage and 0.18 to 0.21 (average $0.20 \pm 0.01$ ) during the mid-season stage. The difference (smaller than 0.03) between the average albedo for the two stages resulted in minimal differences in the $R_{n, s}$ parameterised by $R_{s}$ as previously discussed. Therefore, the crop albedo increased with increasing LAI. Several authors discussing different crops obtained similar results with respect to LAI (Alves et al., 1998; Souza et al., 1999). Sugarcane albedo values reported in the literature show considerable variation. For instance, Andre et al. (2010) found 0.28 and Cabral et al. (2012) measured albedo ranging from 0.15 to 0.23 .

The models estimated $R_{n}\left(\mathrm{~W} \mathrm{~m}^{-2}\right)$ for the crop development and mid-season stages satisfactorily (Fig. 6). The determination coefficients $\left(r^{2}\right)$ between observed and estimated $R_{n}$ for the crop development stage were 0.985 (Orega-Farias model - OFM) and 0.988 (Monteith and 


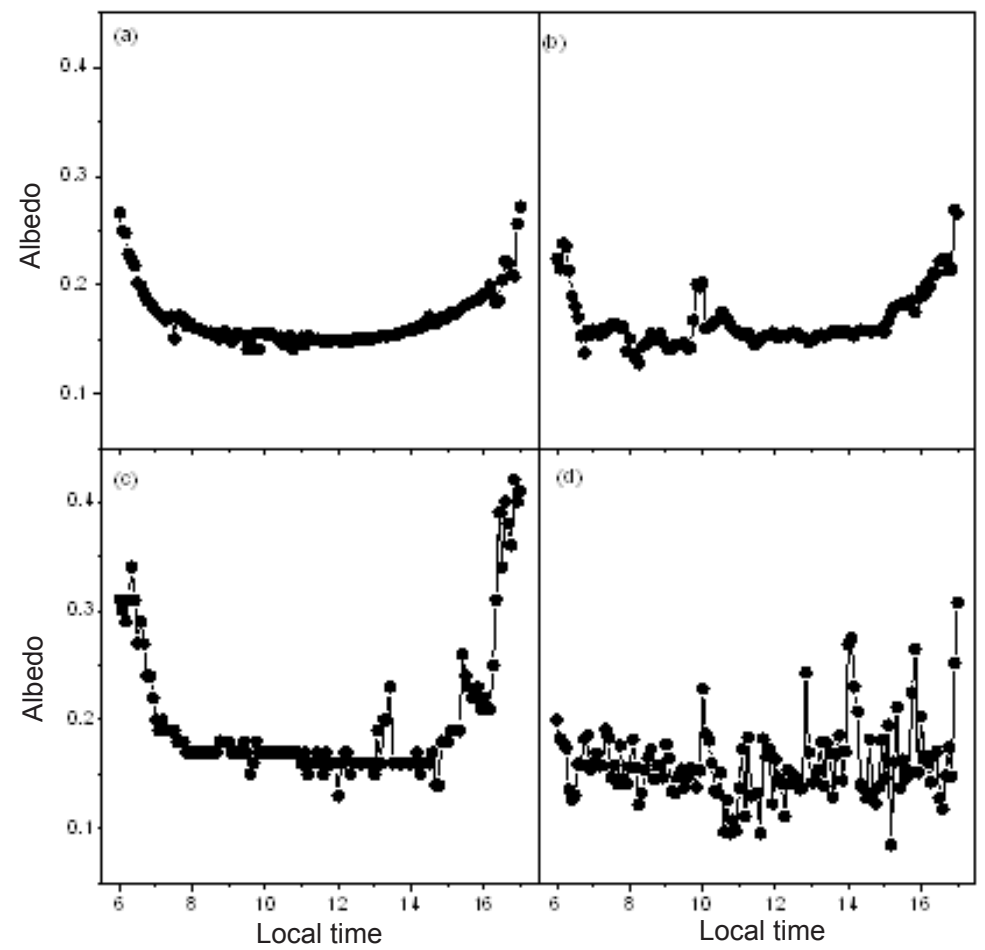

Fig. 5. Albedo of the sugarcane crop under clear sky conditions ( $a, c)$ and partially cloudy sky (b, d) during the crop development stage $(\mathrm{a}, \mathrm{b})$ and mid-season stage $(\mathrm{c}, \mathrm{d})$.

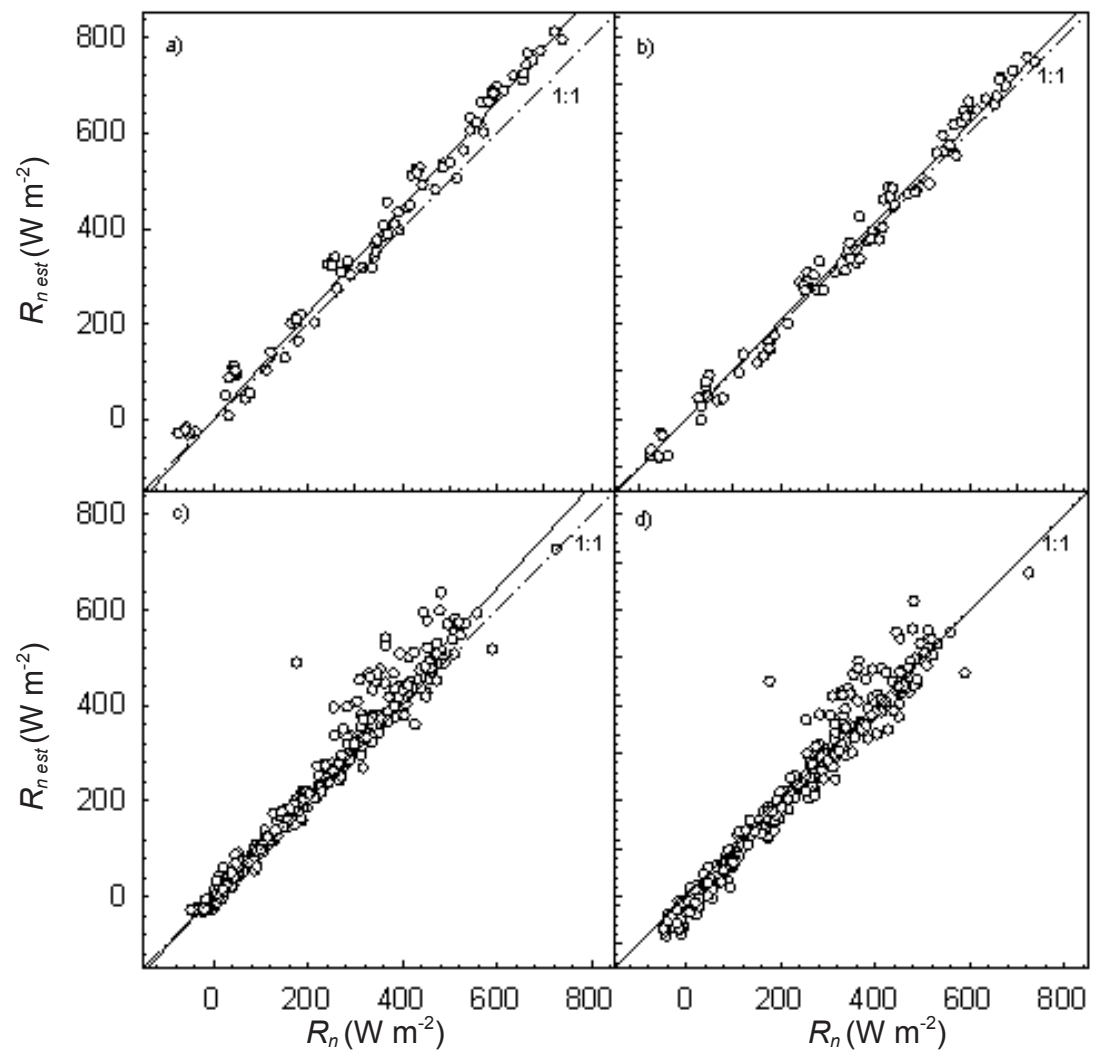

Fig. 6. Relationship between the average observed hourly net radiation $\left(R_{n}\right)$ and the estimated $R_{n}\left(R_{n}\right.$ est $)$ given by OFM (a, c) and MUM $(b, d)$ for the crop development $(a, b)$ and mid-season $(c, d)$ stages. 
Unsworth model - MUM) and for the mid-season stage, 0.958 and 0.955 , respectively. The $r^{2}$ is not able to assess the overall performance of the models, because it measures only how much of the dispersion is explained by the predictions, not being related consistently to the accuracy of the estimates (Krause et al., 2005; Willmott et al., 1985). Additional information about the estimated and observed difference errors is necessary. Willmont et al. (1985) recommend the mean absolute error $(M A E)$ and the root mean square error (RMSE), whereas Krause et al. (2005) recommend the angular coefficient (b) and the intercept (a) of the linear regression between the estimated and observed values upon which $r^{2}$ is based on.

Upon analysing the performance of the models in the two crop growth stages, it can be seen that the $r^{2}$ values of the crop development stage were, for both models, higher than those of the mid-season stage (Table 1). This may be attributed to the use of daily average albedo for estimating hourly $R_{n}$, since the albedo may change considerably during the day (Fig. 5). The estimate errors were larger for the mid-season stage because during this stage the albedo showed larger daily fluctuations. Although the models had higher $\mathrm{r}^{2}$ for the crop development stage (i.e. the models explained the $R_{n}$ variability better), the OFM had higher RMSE and MAE (indicating lower accuracy). These findings reassure that $r^{2}$ should not be the only statistical measure to be used in the evaluation of the models.

A performance analysis of the two models reveals that MUM is superior to OFM in both development stages despite the similarity of their dispersion curves (Fig. 6), with $r^{2}$ values being the same up to the second or third decimal point. Thus, the models were comparable regarding the dispersion of the estimations, but differed regarding their accuracy, as indicated by the RMSE and MAE values as well as by the distances from the line 1:1 (Fig. 6). For both crop stages, OFM had larger RMSE and MAE (Table 1). The overall trend of OFM was to overestimate positive values of $R_{n}$, with a worse performance at the crop development stage. For this crop stage, the averaged $R_{n}$ overestimates by OFM were $11 \%$, as indicated by the angular coefficient of linear regression. The RMSE and MAE of this model for the crop development stage were 55.04 and $47.16 \mathrm{~W} \mathrm{~m}^{-2}$, respectively. Conversely, MUM had its best performance at this crop stage, overestimating $R_{n}$ by only $3 \%$, with RMSE $\left(29.3 \mathrm{~W} \mathrm{~m}^{-2}\right)$ and MAE $\left(24.8 \mathrm{~W} \mathrm{~m}^{-2}\right)$ inferior to those of OFM. OFM had a better performance for the mid-season stage, although inferior to that of MUM. OFM overestimated $R_{n}$ by $8 \%$, whereas MUM had better estimate (underestimating $R_{n}$ by $1 \%$ ).

Both models have a similar formulation to compute $R_{n, s}$, differing only with respect to $R_{n, l}$. The $R_{n, l}$ estimates in OFM are obtained using $R_{l, s}$ and $R_{l, a}$ estimates calculated by the Stefan-Boltzmann law. Two remarks are necessary in the estimation of:

- $R_{l, s}$ the model assumes that $T_{s}$ is equal to $T_{a}$ and,
T a b l e 1. Statistical coefficients of the relation between the observed hourly net radiation and the estimated values obtained with OFM and MUM for the crop development and mid-season stages of a sugarcane crop in Rio Largo region, a coastal area of Alagoas state, Brazil

\begin{tabular}{|c|c|c|c|c|}
\hline \multirow{2}{*}{$\begin{array}{l}\text { Statistical } \\
\text { indices }\end{array}$} & \multicolumn{2}{|c|}{ Crop development } & \multicolumn{2}{|c|}{ Mid-season } \\
\hline & OFM & MUM & OFM & MUM \\
\hline $\mathrm{b}$ & 1.11 & 1.03 & 1.08 & 0.99 \\
\hline$r^{2}$ & 0.983 & 0.988 & 0.958 & 0.949 \\
\hline$R M S E\left(\mathrm{~W} \mathrm{~m}^{-2}\right)$ & 55.04 & 29.27 & 43.41 & 40.94 \\
\hline$M A E\left(\mathrm{~W} \mathrm{~m}^{-2}\right)$ & 47.16 & 24.76 & 25.83 & 30.87 \\
\hline $\mathrm{N}$ & 84 & 84 & 300 & 300 \\
\hline
\end{tabular}

RMSE - root means square error, $M A E$ - mean absolute error, $\mathrm{b}$ - angular coefficient of the linear regression passing through the origin, $\mathrm{r}^{2}-$ determination coefficient and $\mathrm{N}$ number of hourly data used.

- $R_{a}$ the atmospheric emissivity is given by the semi-empirical equation of Brutsaert (Brutsaert, 1982; Ortega-Farias et al., 2000), which is valid only for clear sky conditions. Differently, MUM estimates $R_{n, l}$ use an empirical linear relation given in terms of the air temperature further corrected with respect to $K_{t}$. Therefore, considering that the models did not differ much regarding $R_{n, s}$ estimates and MUM had a better performance, one can infer that the empirical approach used in MUM yields better $R_{n, l}$ estimates despite being less physically based as compared to the OFM approach. Therefore, the difference in performance observed in the two models with respect to the method of calculating $R_{n, l}$ stresses the importance of this variable in estimating $R_{n}$ despite the fact that its contribution is relatively smaller than that of $R_{n, s}$.

One of the reasons OFM had a poorer performance may be attributed to the assumption that the canopy and air temperatures are the same. This assumption is responsible for an overestimate of $R_{n, l}$ during the day, since the two variables do not have the same daily evolution: the surface temperature reaches its maximum around solar noon while the air temperature maximum occurs a few hours later (Ortega-Farias et al., 2000). Furthermore, under soil water deficit conditions $T_{s}$ is generally higher than $T_{a r}$ due to the reduction of transpiration and soil water evaporation (Neukam et al., 2016). However, Carrasco and OrtegaFarias (2008) assessed the estimates of a similar model (the main difference was the change of the coefficient in the Brutsaert equation used to estimate the atmospheric emissivity) applied to a vineyard using two parameterisations:

- $T_{a}$ equal to $T_{s}$ and 


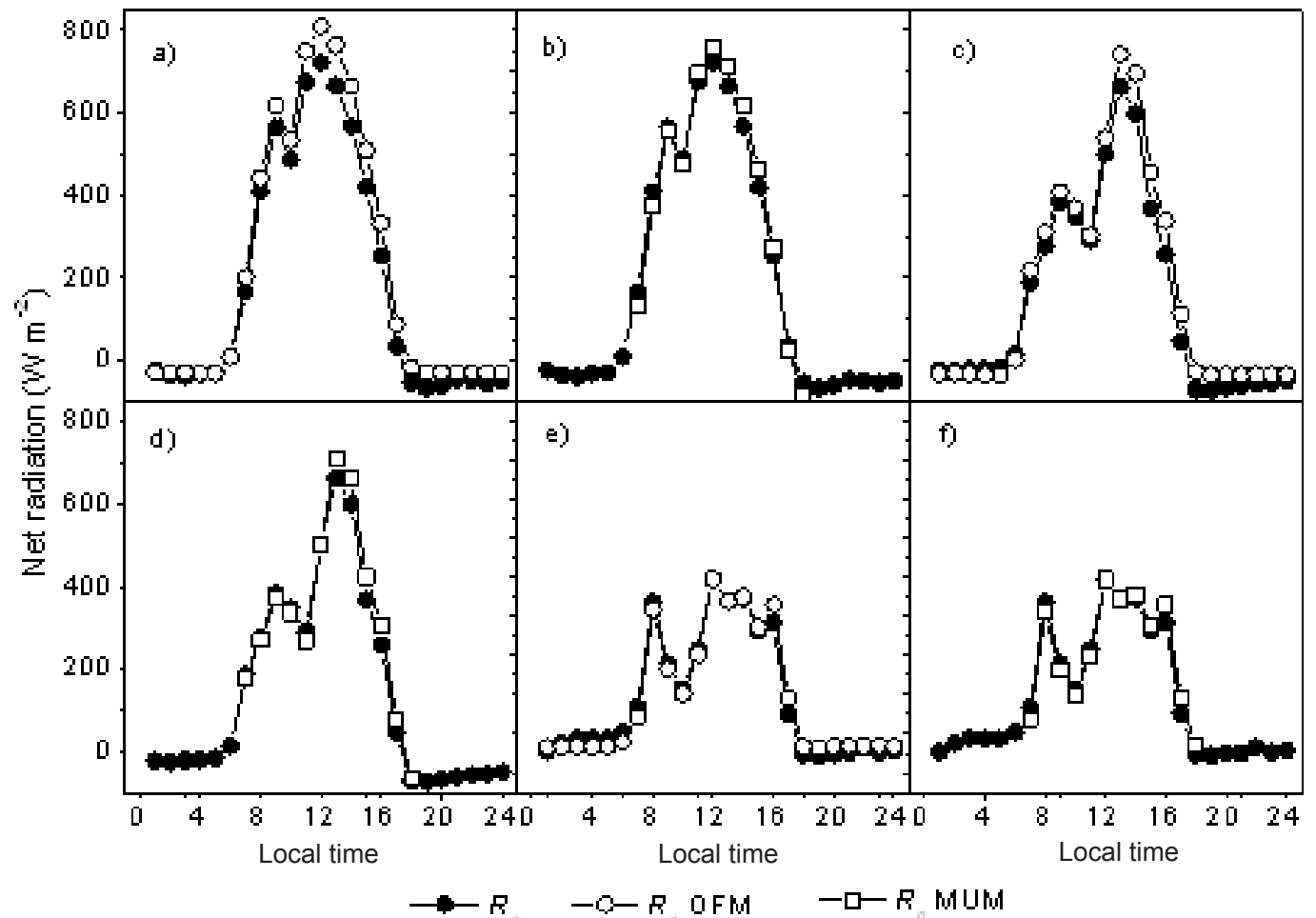

Fig. 7. Net radiation as observed $\left(R_{n}\right)$, and estimated by: the Ortega-Farias $\left(R_{n}\right.$ OFM) model, the Monteith and Unsworth $\left(R_{n}\right.$ MUM) under clear sky condition $(\mathrm{a}, \mathrm{b})$ and partially cloudy sky $(\mathrm{c}, \mathrm{d}, \mathrm{e}, \mathrm{f})$ during the crop development stage.

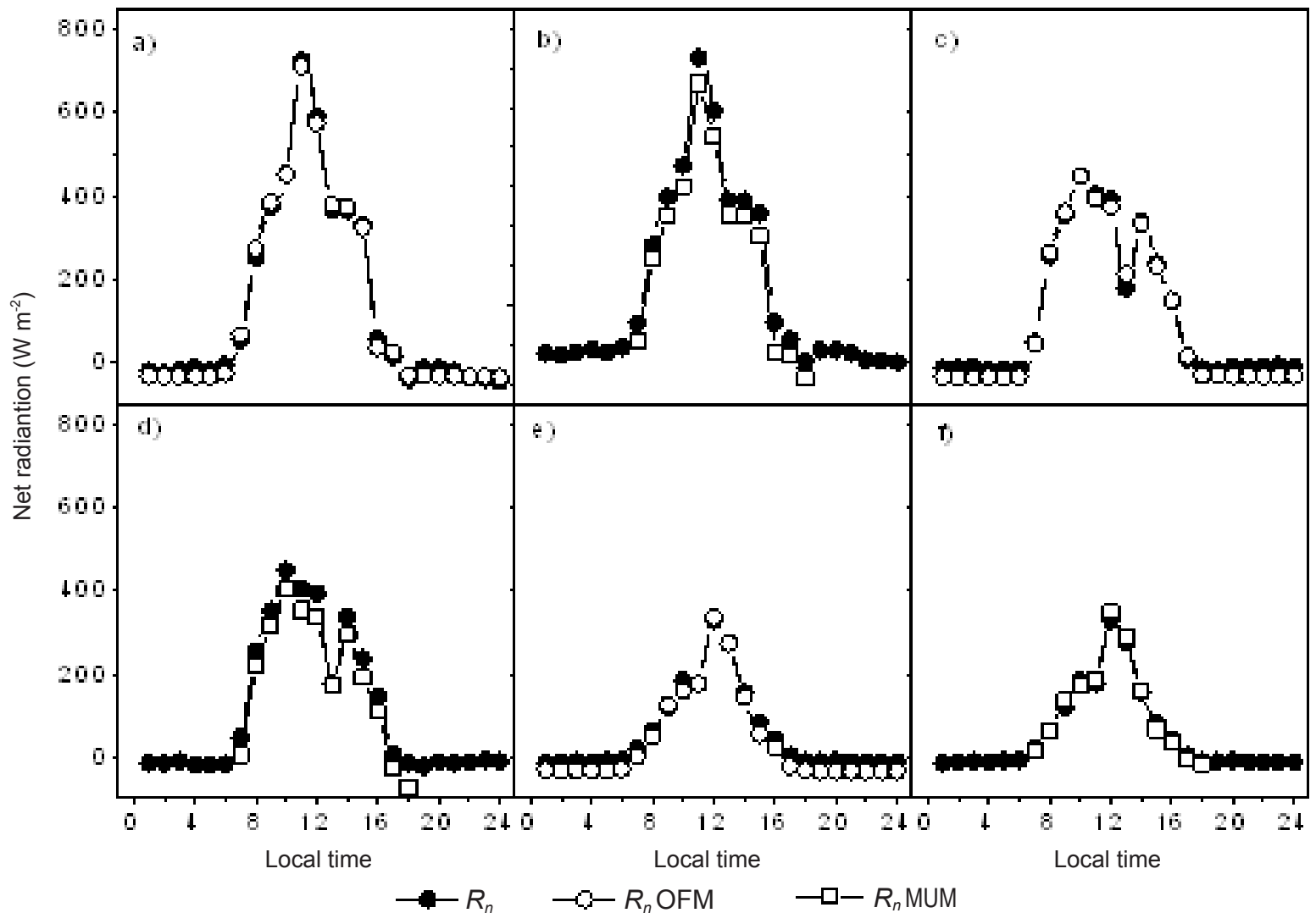

Fig. 8. Net radiation as observed $\left(R_{n}\right)$, and estimated by: the Ortega-Farias $\left(R_{n} \mathrm{OFM}\right)$ model, the Monteith and Unsworth $\left(R_{n}\right.$ MUM) under clear sky condition $(\mathrm{a}, \mathrm{b}, \mathrm{c}, \mathrm{d})$ and partially cloudy sky $(\mathrm{e}, \mathrm{f})$ during the mid-season stage. 
T a b l e 2. Statistical coefficients used in the intercomparisons between observed and estimated net radiation using OFM and MUM under different sky conditions for a sugarcane crop in Rio Largo region, a coastal area of Alagoas state, Brazil

\begin{tabular}{|c|c|c|c|c|c|c|}
\hline \multirow{2}{*}{$\begin{array}{l}\text { Statistical } \\
\text { indices }\end{array}$} & \multicolumn{2}{|c|}{ Clear } & \multicolumn{2}{|c|}{ Partially cloudy } & \multicolumn{2}{|c|}{ Overcast } \\
\hline & OFM & MUM & OFM & MUM & OFM & MUM \\
\hline $\mathrm{b}$ & 1.13 & 1.03 & 1.09 & 1.01 & 0.97 & 1.03 \\
\hline$r^{2}$ & 0.998 & 0.990 & 0.966 & 0.961 & 0.971 & 0.985 \\
\hline $\operatorname{MAE}\left(\mathrm{W} \mathrm{m}^{-2}\right)$ & 65.78 & 27.91 & 29.76 & 29.15 & 17.13 & 11.81 \\
\hline $\operatorname{RMSE}\left(\mathrm{W} \mathrm{m}^{-2}\right)$ & 70.04 & 31.17 & 45.83 & 39.47 & 19.68 & 14.15 \\
\hline $\mathrm{N}$ & 12 & 12 & 720 & 720 & 12 & 12 \\
\hline
\end{tabular}

Explanations as in Table 1.

- $T_{a}$ different from $T_{s}$. They found that using $T_{s}$ to calculate $R_{l, s}$ did not improve the $R_{n}$ estimates, with $M A E$ and $R M S E$ being similar for the two parametrisations.

The authors emphasised that the $T_{a}=T_{s}$ approximation requires that the crops have potential hydric conditions in order to minimise the differences between $T_{a}$ and $T_{s}$, because the soil temperature can yield high values for the sensible heat what, in turn, may cause an increase in the canopy temperature of the crops. This might be the main reason for the inferior performance showed by OFM during the crop development stage when the sugarcane crop did not cover up the soil under conditions of hydric stress.

Another factor besides the hydric stress that explains the low performance of this model is the estimate of the atmospheric emissivity. The value of the coefficient in Brutsaert equation (1.31) considered in the present study was also used by Ortega-Farias et al. (2000) for the Mediterranean climate. This coefficient changes according to the atmospheric conditions of each station (Brutsaert, 1982). Its original value is 1.24 but Carrasco and Ortega-Farias (2008) found values between 1.51 and 1.91. Therefore, it recommended to fit this coefficient to the local conditions.

Although the performance of OFM is inferior to that of MUM, it is comparable to that obtained by Ortegas-Farias et al. (2000) for grass under controlled conditions in two regions with Mediterranean climate. However, the RMSE during the crop development stage was higher than those found by the authors $\left(34\right.$ and $32 \mathrm{~W} \mathrm{~m}^{-2}$ ). Sentelhas and Gillespie (2008) assessed the performance of four models in estimating $R_{n}$ for a grass covered soil. The models differed in terms of complexity of the input meteorological data: the most complex model used $R_{s}, T_{a}, R H$, fraction of sky coverage and cloud heights (the last two variables obtained only at airports), and the simplest one, only $R_{s}$ and $T_{a}$. The $M A E$ varied from 20.3 (for the complex model) to $41 \mathrm{~W} \mathrm{~m}^{-2}$. Except for OFM during the crop development stage, the results of the present study are very close to those obtained by those authors. However, the MUM performance was very similar to that of the complex model of Sentelhas and Gillespie (2008). Our results are also similar to those of Carrasco and Ortega-Farias (2008) obtained with two modified versions of the original model of Ortega-Farias et al. (2000) used for vineyard. Also, the discrepancies are smaller than those found by Jegede (1997) in estimating $R_{n}$ using the method of Fourier Transform in bushes, based only on $T_{a}$.

Due to the non-occurrence of cloudy days during the crop development stage and clear sky during the mid-season stage, only one day was considered in each stage with appropriated $K_{t}$. The models yielded satisfactory results on the daily variation of $R_{n}$ under all sky conditions at both crop stages (Figs 7 and 8). Overestimates of $R_{n}$ using OFM during the crop development stage (Fig. 7) under clear and partially cloudy sky (17 and $15 \%$, respectively) around local midday were observed. OFM gave better $R_{n}$ estimates during the mid-season stage (Fig. 8) with a superior performance for clear or almost clear sky conditions $\left(K_{t}=\right.$ 0.68). Concerning MUM, it was noted that during the crop development stage this model overestimated $R_{n}$ under all sky conditions and underestimated it during the mid-season stage. For the overcast sky condition the MUM showed better precision than the OFM. Independently of the sky conditions, $r^{2}$ values were higher than 0.96 with outstanding performance for the models fitted for clear sky conditions (Table 2). On the other hand, the highest values of $M A E$ and RMSE (65.1 and $70.0 \mathrm{~W} \mathrm{~m}^{-2}$, respectively) were noted for the same sky condition. The smallest (largest) $M A E$ and $R M S E$ values for both models occurred under cloudy sky (clear sky for OFM) condition. Throughout the field experiment there was one day with clear sky condition, taking place at the crop development stage. 


\section{CONCLUSIONS}

1. The net radiation varied with cloudiness, with higher values observed during the crop development stage from November to February, which was the time period of the year with the largest global atmospheric transmittance.

2 . The large values of radiation net longwave found during the crop development stages may be attributed to the high temperatures of the soil-plant system, modulated by the soil water deficit, and consequently, low evapotranspiration.

3. The albedo was higher in the mid-season stage of the crop. The observed and estimated components of the solar radiation for two growth stages of a sugarcane crop in a Rio Largo, Alagoas, Brazil, experimental field were compared.

4. The estimates provided by the two evaluated models were superior for the crop development stage compared to the mid-season stage. The Monteith and Unsworth model was more efficient than the Ortega-Farias model in estimating the net radiation during both growth stages of the crop.

\section{ACKNOWLEDGEMENTS}

The authors thank the National Council of Technological and Scientific Development (CNPq), the Coordination for the Improvement of Higher Education Personnel (CAPES) and the Foundation for Research Support of the State of Alagoas (FAPEAL).

Conflict of interest: The Authors do not declare conflict of interest.

\section{REFERENCES}

Alados I., Foyo-Moreno I., Olmo F.J., and Alados-Arboledas L., 2003. Relation between net radiation and solar radiation for semi-arid shrub-land. Agric. Forest Meteorol., 116, 221-227.

Allen R.G., Pereira L.S., Raes D., and Smith M., 1998. Crop evapotranspiration - Guidelines for computing crop water requirements. Irrig. Drain. Paper 56, Food and Agriculture Organization of the United Nations (FAO), Rome, Italy.

Alves A.V., Azevedo P.V., and Silva B.B., 1998. Energy balance and reflectance of a melon canopy (Portuguese). Rev. Bras. Agrometeorol., 6,139-146.

André R.G.B., Mendonça J.C., Marques V.S., Pinheiro F.M.A., and Marques J., 2010. Energy aspects on the sugar cane development. Part 1: radiation balance and derived parameters (Portuguese). Rev. Bras. Meteorol., 25, 375-382.

Azevedo P.V., Saboya L.M.F., Dantas Neto J., Oliveira F.S., Bezerra J.R.C., and Farias C.H.A., 2014. Availability of energy for sugarcane in the coastal plains of Paraíba state (portuguese). Rev. Bras. Eng. Agríc. Ambient., 18, 1031-1038.

Black T.A., Tanner C.B., and Gardner W.R., 1970. Evapotranspiration from a snap beam crop. Agron J., 62, 66-69.

Brutsaert W., 1982. Evaporarion into the atmosphere. Theory, History and applications. D. Reidel Publishing Company, 229 p.
Cabral O.M.R., Rocha H.R., Gash J.H., Ligo M.A.V., Tatsch J.D., Freitas H.C., and Brasilio E., 2012. Water use in a sugarcane plantation. GCB Bioenergy, 4, 555-565.

Carrasco M. and Ortega-Farías S., 2008. Evaluation of a model to simulate net radiation over a vineyard $c v$. Cabernet Sauvignon. Chil. J. Agr. Res., 67, 156-165.

Fontana D.C., Berlato M.A., and Bergamaschi H., 1991. Energy balance in irrigated and non-irrigated soybeans (Portuguese). Pesq. Agropec. Bras., 26, 403-410.

Idso S.B., Jackson R.D., Ehrler W.L., and Mitchel S.T., 1969. A method for determination of infrared emittance of leaves. Ecology, 50, 899-902.

Inman-Bamber N.G. and Mcglinchay M.G., 2003. Crop coefficients and water-use estimates for sugarcane based on long-term Bowen. Field Crops Res., 83, 125-138.

Iqbal M., 1983. An introduction to solar radiation. Academic Press, New York, USA.

Jegede O.O., 1997. Estimating net radiation from air temperature for diffusion modeling applications in a tropical area. Bound-Lay Meteorol., 85, 161-173.

Kato T., Kimura R., and Kamichica R., 2004. Estimation of evapotranspiration, transpiration ratio and water use efficiency from a sparse canopy using a comportment model. Agric. Water Manag., 65, 173-192.

Krause P., Boyle D.P., and Bäse F., 2005. Comparison of different efficiency criteria for hydrological model assessment. Adv. Geosci., 5, 89-97.

Kustas W.P., Pruegerb J.H., Hippsc L.E., Hatfield J.L., and Meek D., 1998. Inconsistencies in net radiation estimates from use of several models of instruments in a desert environment. Agric. Forest Meteorol., 90, 257-263.

Llasat M.C. and Snyder R.L., 1998. Data error effects on net radiation and evapotranspiration estimation. Agric. Forest Meteorol., 91, 209-221.

Mkhwanazi M.M., Chávez J.L., and Andales A.A., 2015. SEBAL-A: A remote sensing ET algorithm that accounts for advection with limited data. Part I: Development and validation. Remote Sens., 7, 15046-15067.

Monteith J.L. and Unsworth M.H., 1990. Principles of environmental physics. Edward Arnold, London, UK.

Neukam D., Ahrends H., Luig A., Manderscheid R., and Kage H., 2016. Integrating wheat canopy temperatures in crop system models. Agronomy, 6, 1-19.

Ortega-Farias S., Antonioletti R., and Olioso A., 2000. Net radiation model evaluation at an hourly time step for mediterranean conditions. Agronomie, 20, 57-64.

Paltineanu C., Chitu E., and Mateescu E., 2012. New trends for reference evapotranspiration and climatic water deficit. Int. Agrophys., 26, 159-165.

Peng J., Fan W., Xu X., Wang L., Liu Q., Li J., and Zhao P., 2015. Estimating crop albedo in the application of a physical model based on the law of energy conservation and spectral invariants. Remote Sens., 7, 15536-15560.

Sentelhas P.C. and Gillespie T.J., 2008. Estimating hourly net radiation for leaf wetness duration using the Penman Monteith equation. Theor. Appl. Climatol., 91, 205-215.

Souza J.L. and Escobedo J.F., 1997. Radiation budget in green beans crop with and withou polyethylene cover (Portuguese). Pesq. Agropec. Bras., 32, 1-15. 
Souza J.L., Escobedo J.F., and Tornero M.T.T., 1999. Albedo and estimates of net radiation for green beans under polyethylene cover and field conditions (Portuguese). Pesq. Agropec. Bras., 34, 1763-1774.

Souza J.L., Nicácio R.M., and Moura M.A.L., 2005. Global solar radiation measurements in Maceió, Brazil. Renew. Energ., 30, 1203-20.

Souza P.J.O.P., Rocha E.J.P., Ribeiro A., and Souza E.B., 2010. Radiation balance in a soyben ecosystem in the Amazo. Revista Ciência Agronômica, 41, 582-592.

Teixeira A.H.C., 2001. Evaluation of components of energy balance in banana crop during the first year (Portuguese). Rev. Bras. Eng. Agríc. Ambient., 5, 28 -32.

Teixeira A.H.C., Bastiaanssen W.G.M., Ahmad M.D., Moura M.S.B., abd Bos M.G., 2008. Analysis of energy fluxes and vegetation-atmosphere parameters in irrigated and natural ecosystems of semi-arid Brazil. J. Hydrol., 362, 110-127.

Teodoro I., Souza J. L., Barbosa G.V., Moura Filho G., Dantas Neto J., and Abreu M.L., 2009. Growth and yield of sugarcane in rainfed conditions in the tablelands region of Alagoas (Portuguese). Rev. STAB, 27, 31-34.

Willmott C.J., Ackleson S.G., Davis R.E., Feddema J.J., Klink K.M., Legates D.R., O'dnnell J., and Rowe C.M., 1985. Statistics for the evaluation and comparisons of models. J. Geophys. Res., 90, 8995-9005.

Zhang X., Gu S., Zhao X., Cui X., Zhao L., Xu S., Du M., Jiang S., Gao Y., Ma C., Tang Y., 2010. Radiation partitioning and its relation to environmental factors above a meadow ecosystem on the Qinghai-Tibetan Plateau. J. Geophys. Res., 115, 1-8. 